\title{
DIGNIDADE DA PESSOA HUMANA FRENTE À SUPREMACIA DO INTERESSE PÚBLICO SOBRE O PARTICULAR
}

Juciléia de Souza Lima*

\begin{tabular}{l|l}
\hline RECEBIDO EM: & 15.8 .2020 \\
\hline APROVADO EM: & $\mathbf{3 0 . 3 . 2 0 2 1}$ \\
\hline
\end{tabular}

* Doutora e mestre em Direito Tributário pela Faculdade de Direito da Universidade de São Paulo (USP). Fez estágio doutoral na modalidade sanduíche na Universidade de Münster, Alemanha. Especialista em Tributação Internacional pelo Instituto Brasileiro de Direito Tributário (IBDT). Graduada em Direito pela Pontifícia Universidade Católica de Campinas (PUC-Campinas). Leciona Direito Tributário e Processo Tributário na Universidade Presbiteriana Mackenzie em Campinas. Advogada em Campinas (SP). E-mail: jucileialima@alumni.usp.br 
- JUCILÉIA DE SOUZA LIMA

- RESUMO: Este trabalho pretende analisar a dignidade da pessoa humana frente ao princípio da supremacia do interesse público sobre o particular, partindo da consideração de que o princípio da dignidade da pessoa humana passou a ocupar papel nuclear na Constituição Federal de 1988. Sendo assim, o presente trabalho discute um dos principais paradigmas atuais: lidar com o conflito da supremacia do interesse público sobre o particular em matéria de direitos humanos.

- Palavras-chave: Direito administrativo; administração pública; direitos humanos. dignidade da pessoa humana; princípio da supremacia do interesse público.

\section{DIGNITY OF THE HUMAN BEINGS REGARD TO SUPREMACY} OF THE PUBLIC INTEREST OVER THE PRIVATE

ABSTRACT: This paper discusses the dignity of the human person, toward to the principle of the supremacy of the public interest over private, based on the consideration that the of human dignity principle has come to occupy central role in the Federal Constitution of 1988. Thus, this paper discusses one of the main paradigms- to deal with the conflict of the Supremacy of public interest in the field of human rights.

- KEYwords: Administrative law; public administration; human rights; human dignity principle; supremacy of public interest.

\section{Introdução}

A Carta Política de 1988 institucionalizou o Estado Democrático de Direito no Brasil assegurando, como um de seus fundamentos, a dignidade da pessoa humana, conforme exposto nos incisos II e III do art. $1^{\circ}$, da Constituição Federal.

Ao romper com a sistemática das Cartas Políticas anteriores, a Constituição Federal de 1988 conferiu nova topografia aos direitos individuais, ineditamente consagrando o primado do respeito aos direitos humanos e o cristalino rompimento paradigmático da lente estatal ex parte principe para a lente ex parte populi. 
A Constituição confere unidade de sentido, valor e concordância prática ao sistema dos direitos fundamentais e nela repousa a dignidade da pessoa humana, ou seja, na concepção que torna a pessoa fundamento e fim da sociedade e do Estado.

Na ordem constitucional vigente, o princípio da dignidade humana compõe a tônica do neoconstitucionalismo em lugar dos antigos conceitos de soberania nacional e de não intervenção.

Nesse contexto, a Constituição deve ser compreendida como unidade e como sistema que irradia determinados valores sociais, especialmente o da dignidade humana, alocado como valor essencial que informa a toda ordem constitucional.

A primazia jurídica do valor da dignidade humana passou a orientar o direito interno como o Direito Internacional, pois unifica e centraliza todo o sistema normativo, assumindo especial prioridade, além de conferir suporte axiológico a todo o sistema jurídico brasileiro.

\subsection{A “constitucionalização" e a "internacionalização" dos direitos humanos}

Em 1988, a Constituição Federal passou a indicar, em seu artigo $1^{\circ}$, os fundamentos da República Federativa do Brasil, entre eles, no inciso III, a dignidade da pessoa humana. Entretanto, desde 22 de novembro de 1969, durante a Conferência Especializada Interamericana sobre Direitos Humanos, o Brasil já tinha assinado o Pacto de San José da Costa Rica, ${ }^{1}$ muito anterior à promulgação do texto constitucional, apesar de ter sido ratificada somente em 25 de setembro de 1992.

1 Na sua primeira parte, o Pacto de San José da Costa Rica, enumera os deveres dos Estados: obrigação de respeitar os direitos, considerar que toda pessoa é ser humano e dever de adotar disposições de direitos interno. Os direitos considerados protegidos pela Convenção Americana de Direitos Humanos são os seguintes: direito à vida; direito à integridade pessoal; proibição da escravidão e da servidão; direito à liberdade pessoal; garantias judiciais; princípio da legalidade e da retroatividade; direito à indenização; proteção da honra e da dignidade; liberdade de consciência e de religião; liberdade de pensamento e de expressão; direito de retificação ou resposta; direito de reunião; liberdade de associação; proteção da família; direito ao nome; direitos da criança; direito à nacionalidade; direito à propriedade privada; direito de circulação e de residência; direitos políticos; igualdade perante a lei; proteção judicial; desenvolvimento progressivo. Além disso, o Pacto de San José da Costa Rica estabelece os deveres das pessoas e indica, como foro de discussões e arbitragem para eventuais desrespeitos aos seus mandamentos, a Comissão Interamericana de Direitos Humanos e Corte Interamericana de Direitos Humanos, localizada em San José da Costa Rica. Com relação à proteção aos direitos humanos, em 2004, a Emenda Constitucional no 45 acrescentou o $\$ 4^{\circ}$ ao artigo $5^{\circ}$ da Constituição Federal de 1988, determinando que o Brasil se submeta à jurisdição do Tribunal Penal Internacional. 
Todavia, a possível razão para a tardia ratificação pode estar no fato de que o Brasil, naquele período, vivia um regime de exceção, não aceitando os governantes daquela época qualquer ingerência externa nos assuntos considerados de ordem pública.

A consolidação dos direitos humanos e das instituições democráticas positivadas no texto constitucional mudou substancialmente a política externa brasileira, surgindo, ao Estado Brasileiro, a obrigatoriedade de instituir políticas locais que assegurassem o cumprimento de obrigações assumidas plano internacional.

\section{Dignidade da pessoa humana: conceito}

A Declaração Universal dos Direitos Humanos, promulgada em Paris na Assembléia Geral da ONU em 1948, após a Segunda Grande Guerra, deu aos direitos humanos um espaço central nas agendas política dos países.

Em 1945, foi instituído o Tribunal de Nuremberg, incumbido de julgar os crimes contra a humanidade. Posteriormente, surgiram outros pactos visando garantir a efetivação dos direitos humanos, como a Convenção sobre o Estatuto dos Refugiados (1951), o Pacto Internacional dos Direitos Civis e Políticos (1966) e o Pacto dos Direitos Econômicos, Sociais e Culturais (1966). Apesar desses pactos terem sido aprovados pela Assembleia Geral das Nações Unidas em 1966, esses pactos só foram ratificados pelos Estados a partir de 1976, e, no caso do Brasil, tais pactos só foram ratificados pelo Congresso Nacional em 24 de janeiro de 1992.

No Continente Americano, por intermédio da Organização dos Estados Americanos (OEA), em 2 de abril de 1948, na Declaração Americana dos Direitos e Deveres do Homem estava previsto, em seu preâmbulo, que os direitos essenciais do homem não derivam do fato de ser ele cidadão de determinado Estado, mas, sim, de esses direitos serem inerentes à pessoa humana.

Entretanto, o termo direitos humanos apresenta grande amplitude para as suas interpretação e compreensão, sendo uma tarefa complexa contextualizá-lo. Para Bobbio (1992), os direitos humanos possuem semelhante natureza aos direitos naturais universais, que, para ganharem efetividade, dependem da positivação do ordenamento jurídico de cada Estado.

Herkenhoff (2010) entende que os direitos humanos são decorrentes da própria natureza humana do indivíduo, por ser, primariamente, homem ou mulher, logo, não representando qualquer concessão do Estado ou da sociedade política. 
Por sua vez, Joaquín Herrera Flores (2009) defende que os direitos humanos são fruto do processo social e de lutas sociais e coletivas no seio social pelo apoderamento de espaços públicos e por maior influência política na sociedade.

Norberto Bobbio (2014) ainda aponta que o princípio da dignidade da pessoa humana evoluiu gradativamente em três fases da vida social. Na primeira fase, os direitos decorriam de correntes filosóficas defendidas na academia; na segunda, os direitos passaram a ser inseridos em textos legais no âmbito nacional; por fim, na terceira fase, os direitos tiveram um alcance mundial, tal como foi expressado na Declaração Universal dos Direitos Humanos em 1948.

Entretanto, o autor também reconhece que existe um distanciamento entre a teorização do princípio da dignidade da pessoa humana e sua real efetividade, já que cabe, singularmente, a cada Estado empenhar-se para dar efetividade aos direitos a ele inerentes, o que pode ser comprometido pela ausência de recursos financeiros ou pela ausência de vontade política.

No mesmo inciso III do artigo $1^{\circ}$ da Constituição de 1988 está a dignidade da pessoa humana. O artigo 170 estabelece que a ordem econômica, fundada na valorização do trabalho humano e na livre iniciativa, tem por fim assegurar existência digna a todos, conforme os ditames da justiça social, apontando princípios a serem observados; os que dizem respeito à dignidade da pessoa humana são o da redução das desigualdades regionais e sociais e o da busca do pleno emprego.

$\mathrm{O}$ artigo 226, $\$ 7^{\circ}$ da Constituição Federal, no capítulo que trata da família, da criança, do adolescente e do idoso, prevê o planejamento familiar, fundado nos princípios da dignidade da pessoa humana e da paternidade responsável, ao ser livre decisão do casal, competindo ao Estado propiciar recursos educacionais e científicos para o exercício desse direito, vedada qualquer forma coercitiva por parte de instituições oficiais ou privadas.

O artigo 227 atribui à família, à sociedade e ao Estado o dever de assegurar à criança e ao adolescente, com absoluta prioridade, o direito à vida, à saúde, à alimentação, à educação, ao lazer, à profissionalização, à cultura, à dignidade, ao respeito, à liberdade e à convivência familiar e comunitária, além de colocá-los a salvo de toda forma de negligência, discriminação, exploração, violência, crueldade e opressão.

Por fim, no artigo 230, é atribuído à família, à sociedade e ao Estado o dever de amparar as pessoas idosas, assegurando sua participação na comunidade, defendendo sua dignidade e bem-estar e garantindo-lhes o direito à vida. 
Esses são os principais dispositivos constitucionais que explicitam o princípio da dignidade da pessoa humana, o que, por obviedade, não esgota o seu conteúdo por ser um direito inerente à natureza humana, expressando direitos individuais, sejam eles econômicos, políticos, sociais, culturais ou de qualquer outra natureza, previstos em Constituições, em Declarações de Direitos ou em leis infraconstitucionais.

\subsection{A dignidade da pessoa humana: princípio, valor ou norma?}

A Professora Maria Sylvia Zanella Di Pietro (2014) questiona sobre a natureza jurídica do princípio da dignidade da pessoa humana, isto é, se seria a dignidade da pessoa humana um mero valor, um princípio ou uma regra. Por isso, indica também que o princípio da dignidade da pessoa humana tem a natureza de um valor supremo positivado no preâmbulo da Constituição, ainda, de princípio constitucional, que tem por objetivo garantir a centralidade da pessoa humana, bem como de regra a ser observada para dar efetividade ao valor e ao princípio.

A dignidade da pessoa humana atrai o conteúdo de todos os direitos fundamentais do homem, bem como, representa um valor supremo fundante da República, da democracia e do direito. Então, não se poderia dizer que é apenas um princípio da ordem jurídica, mas o é, também, das ordens política, social, econômica e cultural.

Entretanto, importante distinção faz Valdés (2015) entre "valores" e "princípios", ao defender que os princípios são proposições que estão na base do ordenamento jurídico, significando princípio, origem, causa, gênesis do ordenamento jurídico, enquanto os valores superiores se entendem como meta, fim, critério axiológico do Direito.

Por isso, Di Pietro (2014) ainda leciona que a dignidade da pessoa humana tem a natureza de princípio que representa um valor fundante - um ideal a ser alcançado - que precede a Constituição Federal, no sentido de origem, causa e gênesis do ordenamento jurídico de uma sociedade, que existe independentemente da existência do Estado e de sua positivação nos textos legais.

Entretanto, as tentativas dispendidas para diferenciar as regras dos princípios não apresentaram um critério de prevalência e de ponderação quando existente uma situação de colisão entre esses valores.

Por isso, erigido no preâmbulo da Constituição e em seu artigo $1^{\circ}$, a dignidade da pessoa humana deve ser considerada, abstratamente, como valor (ideal a ser atingido) $e$ 
como princípio inerente ao Estado de Direito Democrático. Com essa natureza de valor e de princípio, a dignidade da pessoa humana deve nortear a aplicação do direito, para a interpretação das regras jurídicas e para integração em caso de lacuna da lei.

Sendo assim, o princípio da dignidade da pessoa humana serve de inspiração e base para positivação das normas constitucionais, estas que, sim, têm natureza de regras, visando a garantir a observância do princípio da dignidade da pessoa humana.

\section{A dignidade da pessoa humana e a Administração Pública}

Apesar da positivação do princípio da dignidade da pessoa humana na Constituição Federal, seja interpretado como valor, princípio ou norma, as disposições legais ainda têm força suficiente de concretização dos direitos ali assegurados.

A Constituição Federal de 1988 aumentou significativamente a demanda por justiça na sociedade brasileira, inclusive na relação entre a Administração Pública e os administrados, que, em primeiro lugar, a demanda por justiça decorre da redescoberta da cidadania e pela conscientização das pessoas em relação aos próprios direitos, e, em segundo, pela criação de novos direitos sociais no texto constitucional.

Sendo assim, a constitucionalização de diversos direitos sociais aumentou a demanda por justiça e acesso ao Judiciário, especialmente referente à adoção de políticas públicas que sejam aptas a realizar os direitos sociais, embasados no princípio da dignidade da pessoa humana.

Os temas judicializados que batem à porta do Judiciário com maior frequência, normalmente, têm a ver com o controle de políticas públicas, especialmente os de caráter social, como saúde, educação, previdência e assistência social.

Todavia, atualmente, a questão do controle das políticas públicas envolve a necessidade de ponderação entre o limite adequado para o exercício do direito constitucionalmente assegurado e a questão do poder da decisão judicial capaz de realocar recursos públicos, tendo sua destinação previamente decidida pelos Poderes Legislativo e Executivo.

A judicialização excessiva de direitos concernentes ao princípio da dignidade humana tem sido largamente invocada, em um processo em que o juiz desconhece os efeitos de sua decisão sobre a alocação de recursos públicos que deveriam ser destinados a uma área específica decidida pelo Legislativo ou pelo Executivo e que, por força de uma decisão judicial, acabam sendo destinados a outra área estranha. 


\subsection{Regime jurídico da Administração Pública}

A relevância da disposição de um regime jurídico para a atuação da Administração Pública - o Direito Administrativo - tem como pedra angular dois princípios: a supremacia do interesse público sobre o privado e a indisponibilidade dos interesses públicos.

Bandeira de Mello (2005) expõe que o princípio da supremacia do interesse público representa um verdadeiro axioma ao revelar a superioridade do interesse da coletividade sobre o particular. Todavia, ele adverte que as prerrogativas e os privilégios decorrentes da supremacia do interesse público somente pode ser empregada na exata consecução do interesse público, sob pena de tornar-se ilegítima a atividade administrativa.

Di Pietro (2006) sustenta que o regime administrativo resume-se basicamente a prerrogativas e sujeições. O Direito Administrativo gravitaria em torno da oposição bipolar das ideias de liberdade do indivíduo e autoridade da Administração, resultando a esta um conjunto de restrições e prerrogativas. Essas restrições serviriam para assegurar a liberdade do indivíduo a partir da obediência ao princípio da legalidade administrativa. As prerrogativas e privilégios da Administração garantiriam a autoridade necessária à consecução de seus fins em privilégio à supremacia do interesse público sobre o particular.

Sendo assim, não é forçoso concluir que a supremacia do interesse público decorre da posição privilegiada do órgão administrador do interesse público e sua posição de supremacia em relação aos administrados.

Todavia, o princípio da indisponibilidade do interesse público não se encontra à livre disposição de quem quer que seja, não podendo ser passível de ser apossado por terceiros que não sejam a própria Administração Pública.

\subsection{Supremacia do interesse público sobre o privado}

O Direito Administrativo, enquanto disciplina jurídica autônoma, possui regras e princípios próprios e sistematizados que lhe dão identidade e o diferencia dos demais ramos do Direito, possuindo princípios que lhe são específicos, entre eles, o princípio da supremacia do interesse público sobre o privado, partindo da atuação pautada na proteção dos interesses da coletividade e pautado por prerrogativas e sujeições.

Para garantir que a Administração Pública atinja seus fins, foram-lhe outorgados prerrogativas e privilégios a assegurar a supremacia do interesse público sobre o particular. Já no tocante às restrições, a Administração Pública se sujeita às limitações legais 
que, se não observadas, implicam em desvio de poder e, consequentemente, à nulidade dos atos praticados.

Responsável pelas necessidades singulares e concretas, a supremacia do interesse da Administração Pública lhe destina notória diferenciação do ente público em relação ao particular como instrumento de legitimação e de conveniência a garantir a implementação das medidas administrativas essencias à efetividade do interesse público.

Portanto, o princípio da supremacia do interesse público sobre o privado corresponde à verticalidade das relações existentes entre o público e o privado, importando, sempre, o desequilíbrio natural a favor do ente estatal.

Osório (2000) adota uma postura reducionista ao defender que o princípio da supremacia do interesse público está implícito na ordem constitucional brasileira dado que a Constituição seria repleta de situações que impõem a superioridade do Estado com vistas a atingir seu fim - que é a satisfação do interesse público.

Diante da ausência de uma norma constitucional expressa que assegure o princípio da supremacia do interesse público, Osório ainda defende tratar-se de um princípio implícito, decorrente da própria ordem jurídica, legitimando o regime de normas de privilégio conferido à Administração Pública para a consecução de seus fins.

Todavia, não parece ser razoável a posição adotada pelo autor, já que não parece ser possível extrair da Constituição um princípio que assegure (prima facie) a supremacia do interesse público, a menos que tal assertiva estivesse expressamente prevista no texto constitucional, o que não acontece. Ademais, não se pode olvidar que a ideia de supremacia do interesse público depende da ponderação de valores e princípios constitucionais em jogo, os quais não são considerados pela visão reducionista em questão.

Todavia, a problemática aparece quando a autoridade administrativa é exercida quando a função administrativa é realizada para a satisfação de interesses privados estranhos à coletividade.

Nesse contexto, Borges (2006), ao tratar do desvio de finalidade no exercício da supremacia do interesse público, reconhece que, se a Administração Pública no exercício de suas funções não pudesse usar, por exemplo, de certas prerrogativas de potestade pública, tais como a imperatividade, a exigibilidade e a presunção de legitimidade dos seus atos, nem, em circunstâncias especiais perfeitamente delineadas pela lei, a autoexecutoriedade de seus atos poderiam não ter efeito social, por consequência, seria um caos. Todavia, não se pode confundir a supremacia do interesse público - alicerce das estruturas democráticas, pilar do regime jurídico-administrativo - com as suas ma- 
nipulações e desvirtuamentos em prol do autoritarismo retrógrado e reacionário de certas autoridades administrativas, afirmando que o problema pois, não é o princípio, é, antes, sua aplicação prática.

Aragão (2007) apresenta uma posição menos reducionista que a demonstrada pela tradicional doutrina administrativa, justificando que não existe interesse público, abstratamente, considerado que deva prevalecer sobre o interesse privado, haja vista, ser a atividade regulatória do Estado bem mais complexa do que a singela formulação do princípio na doutrina administrativista.

A posição defendida por Osório (2000) recebeu inúmeras críticas, ocasião em que muitos se opuseram a essa posição, especialmente, contestando a existência do princípio em pauta ou para dar a ele uma nova formulação, mais compatível com o estatuto axiológico do Estado Democrático de Direito. Importante contribuição ao tema deu Schier (2007), ao invocar a necessidade da compreensão da Constituição como um sistema, sendo, então, os interesses (ou direitos) públicos e privados equiparados entre si e não prevalentes um sobre o outro. Os interesses públicos não devem ser compreendidos como superiores aos privados, já que ambos são reconhecidos na Constituição em condição de igualdade, bem como estão repousados em pé de igualdade.

Schier ainda enfatiza que se o texto constitucional, em algumas situações, na ponderação de princípios e direitos in abstracto, reconhece previamente a prevalência desses interesses e não de supremacia do interesse público não está autorizado a extração do princípio da supremacia do interesse público sobre o privado do texto constitucional. Pois, se assim fosse, isso não explicaria os casos em que o texto fundamental faz a opção diversa; quando, ponderando in abstracto, reconhece previamente a prevalência dos direitos, liberdades e garantias individuais.

Schier (2007), partindo da perspectiva de Ronald Dworkin, admite a existência de um princípio material do interesse público, mas jamais a existência de um princípio que afirme a sua supremacia.

Por sua vez, Ávila (2007) defende a inexistência de prevalência dos interesses públicos sobre o particular, apesar de aceitar que a Administração Pública deve orientar-se pelo atendimento ao interesse público, o que não significa e nem poderia significar que se estabeleça uma relação de prevalência do interesse público sobre o particular.

Ademais, ainda assevera Ávila que o interesse público tem como finalidade fundamental o desenvolvimento da atividade estatal, enquanto a supremacia do interesse público sobre o particular não denota o mesmo significado. 
Para Ávila (2007), os elementos privados estão incluídos nos próprios fins do Estado - por exemplo, preâmbulo e direitos fundamentais -, por isso, admitir a supremacia do interesse público sobre o particular é o mesmo que aceitar que exista uma relação de conflito entre eles, o que não existe, não havendo o que se alegar em prevalência ou em supremacia do interesse público.

Häberle (Apud Ávila: 2007, p. 14), que se referia à Lei Fundamental Alemã, leciona que o interesse privado é um ponto de vista que faz parte do conteúdo de bem comum da Constituição, em vez da existência de qualquer relação de contradição entre os interesses privado e público, defende existir, somente, uma "conexão estrutural” (ein struktureller Zusammenhang).

Daniel Sarmento (2007) apresenta uma postura intermediária ao tratar do tema, propondo uma posição que nos parece mais adequada ao afirmar que aceitar a supremacia do interesse público sobre o particular, do ponto de vista de uma teoria moral, pode ser justificável, a partir de duas perspectivas diversas: o organicismo e o utilitarismo. ${ }^{2}$

Por outro lado, a tese da supremacia do interesse privado sobre o particular assenta-se tão somente no individualismo, o que não parece ser justificável. E a posição que defende Sarmento (2007) é que a prevalência deve ser aferida mediante uma ponderação equilibrada entre interesses públicos e privados, pautada pelo princípio da proporcionalidade e não atropelada por uma hipotética supremacia do interesse público.

\section{A constitucionalização do direito e a centralidade da pessoa humana}

A constitucionalização da atuação do Poder Público se reverbera sobre a estrutura e a organização do Estado, ao exigir do administrador público o cumprimento de deveres negativos e positivos para a sua atuação em obediência aos limites e aos fins ditados pela Constituição.

2 Cf. o autor, organicismo é uma teoria que concebe as comunidades políticas como espécie de "todo vivo", composto por indivíduos que nela desempenham papel semelhante a um órgão dentro do corpo humano. Para o organicismo, as comunidades políticas possuem fins, valores e objetivos próprios que transcendem o interesse privado, valorizando sempre o interesse público em detrimento do privado. Enquanto no utilitarismo, os interesses individuais devem ser promovidos a partir da escolha racional dos indivíduos, maximizadas pelo bem-estar, o prazer, a felicidade ou as preferências racionais dos agentes políticos. Segundo a doutrina de Jeremy Bentham, Stuart Mill e Adam Smith, os interesses coletivos devem ser perseguidos desde que não contrarie o interesse da maioria. SARMENTO, Daniel. Interesses privados na perspectiva da teoria e da filosofia constitucional. In: SARMENTO, Daniel. Interesses públicos versus interesses privados: descontruindo o Princípio de Supremacia do Interesse Público. Rio de Janeiro. Lumen Juris Editora, 2007, p. 52- 61. 
Barroso (2008) expõe que existem três circunstâncias que devem ser consideradas no âmbito da constitucionalização da atuação do Poder Público: a existência de uma vasta quantidade de normas constitucionais que visam disciplinar a atuação do Poder Público; a sequência de transformações sofridas pelo Estado brasileiro nos últimos anos; e a influência dos princípios constitucionais sobre a atuação do Poder Público.

A Constituição Federal discorre amplamente sobre a atuação da Administração Pública, além de conter, detalhadamente, um autêntico e prolixo estatuto dos servidores públicos, radiando diretamente verdadeiros princípios constitucionais sobre a atividade administrativa.

Barroso ainda observa que o Direito Constitucional e o Direito Administrativo passaram, nas últimas décadas, por transformações profundas que superaram ideias tradicionais, introduzindo conceitos novos e suscitarando perplexidades ainda não inteiramente equacionadas. Todavia, faz-se mister a constante realização de juízos de ponderação, com o propósito de proporcionar uma acomodação desses valores. Os juízos de ponderação são necessários em todas as etapas do processo jurídico, desde a matriz constitucional até as fases posteriores de concretização legislativa, administrativa e jurisdicional.

Os grandes temas constitucionais também ensejam a renovação do Direito Administrativo, exigindo novos olhares que serão ou incorporados ou, às vezes, supressores daqueles tradicionais do Direito Administrativo.

Por fim, mais decisiva para a constitucionalização do Direito Administrativo foi a incidência no seu domínio dos princípios constitucionais que incidem por todo o sistema jurídico. Daqui, também parte a centralidade da dignidade humana e da preservação dos direitos fundamentais, o que pode alterar as relações com a Administração Pública, superando e reformulando os paradigmas tradicionais.

\subsection{A constitucionalização e judicialização das relações sociais}

A Constituição Federal de 1988 criou novos direitos que legitimaram as reinvindicações entre administrados e a Administração Pública, seja pela redescoberta seja pela conscientização popular da existência desses direitos.

Outrossim, não se pode olvidar que tal fenômeno caracterizou o Poder Judiciário como um importante player da sociedade brasileira por dar a ele, o Poder Judiciário, 
notória ascensão institucional ante a judicialização massificada de questões sociais e políticas relacionadas ao modelo institucional brasileiro.

As principais questões judicializadas são as atinentes ao controle de políticas públicas em matéria de direitos fundamentais, que na maioria dos casos, pleiteiam, ora o controle político-social, ora o controle jurídico no espaço democrático.

Se por um lado, a doutrina pátria vem se posicionando de forma favorável ao controle jurisdicional de políticas públicas, sabe-se que, por questões de ordem orçamentária e financeira, existem limites para o atendimento dos pleitos da sociedade civil. Isso ocorre em virtude, principalmente, do fato de que os recursos públicos são finitos e escassos diante do imenso rol de necessidades envolvendo os direitos sociais, por isso, vem a doutrina apresentando, via de regra, alguns limitadores à concessão de tais direitos, a saber: a garantia do mínimo existencial e o da reserva do possível.

Ante a escassez dos recursos públicos, o administrador público deve aplicá-los, preferencialmente, na prestação de serviços essenciais a assegurar o mínimo existencial à população.

A garantia do mínimo existencial busca proporcionar a otimização dos gastos públicos na implementação das políticas públicas em prol do atendimento das necessidades sociais e da garantia da dignidade humana.

Sendo assim, o conceito de mínimo existencial exerce um papel nuclear na interpretação dos valores constitucionais da dignidade da pessoa humana. O mínimo existencial assegura o direitoà vida sob as condições mínimas de existência humana digna que se desdobra na obrigação positiva por parte do Estado em instituir e implementar as políticas públicas. Todavia, uma vez descumprida a obrigação estatal, justifica-se a intervenção do Judiciário no controle de tais políticas públicas para corrigir seus rumos ou implementá-las.

Entretanto, a reserva do possível constitui um elemento "limitador fático-jurídico" para o acolhimento de demandas envolvendo o Poder Público.

Diante do quadro tensional apresentado, o Poder Judiciário vem sendo provocado, reiteramente, a se pronunciar sobre o controle de políticas públicas e na concretização de direitos sociais. Entretanto, Barroso (2008) alerta que, se por um lado, a Constituição protege os direitos fundamentais e determina a realização de políticas públicas, por outro, atribui as decisões sobre o investimento de recursos e as opções políticas a serem perseguidas, a cada tempo, aos Poderes Legislativo e Executivo.

Barroso complementa que a Constituição Federal tem a sua própria supremacia assegurada, mas não existe hegemonia judicial, por isso, deve a doutrina voltar a 
sua atenção para o desenvolvimento de parâmetros objetivos de controle de políticas públicas.

Embora o debate, na sua essência, seja universal e gravite em torno das tensões e superposições entre constitucionalismo e valores constitucionais, especialmente, o da efetividade do princípio da dignidade da pessoa humana no Estado Democrático de Direito. O papel do Judiciário e, especialmente, das cortes constitucionais e dos tribunais superiores deve ser o de resguardar o processo democrático e promover o valores constitucionais, superando o déficit de legitimidade dos demais poderes, em caso excepcional, sem, contudo, desqualificar a própria atuação, exercendo preferências políticas de modo voluntarista.

Para tanto, Barroso defende que as regras têm preferência sobre princípios, desde que, sob igual hierarquia, não tenha sido possível solucionar a colisão entre eles pelos mecanismos tradicionais de interpretação. Outrossim, o autor faz uma importante observação dogmática: os princípios têm uma área nuclear que se aplica como regra. Regras têm padrão geral, não devendo ser ponderadas. Quando o constituinte ou o legislador atuam por meio de uma regra, expressa um mandado definitivo e não uma ordem de otimização, ou seja, ele faz uma escolha que deve ser respeitada pelo intérprete. A não realização dos efeitos de uma regra significa, de ordinário, sua violação. Sendo assim, ao prover acerca de um tema por meio de regra, o constituinte-legislador ou excepcionou deliberadamente um princípio ou optou por prestigiar a segurança jurídica em detrimento da flexibilidade, minimizando a intervenção do intérprete judicial.

Por assim, a constitucionalização do direito, na acepção apresentada neste artigo, identifica o efeito expansivo das normas constitucionais, cujas regras e princípios se irradiam por todo o sistema jurídico. Da constitucionalização, decorre a aplicabilidade direta e imediata da Constituição a diversas situações, a inconstitucionalidade das normas incompatíveis com a Lei Fundamental e, sobretudo, a interpretação das normas infraconstitucionais conforme a Constituição, bem como dos princípios nucleares, tal como o é o da dignidade da pessoa humana que deve se conformar com o sentido e o alcance das normas constitucionais.

Malgrado exista o fenômeno positivo compatível com o Estado democrático e com maior potencial de realização dos direitos fundamentais consubstanciados na dignidade da pessoa humana, não deve passar despercebido o fato de que a judicialização exacerbada concernente ao controle de políticas públicas pode trazer consequên- 
cias que impactam negativamente sobre o processo democrático e sobre o orçamento público, duas das quais já foram apontadas por Barroso (2007, p. 31- 63), a saber: (i) de natureza política o esvaziamento do poder das maiorias, pelo engessamento da legislação ordinária; (ii) de natureza metodológica: o decisionismo judicial, potencializado pela textura aberta e vaga das normas constitucionais.

Por tudo, igual posição a de Barroso, defendemos neste paper a necessidade de que juízes e tribunais adotem certo rigor dogmático e assumam o ônus argumentativo da aplicação de regras que contenham conceitos jurídicos indeterminados ou princípios de conteúdo fluido. O uso abusivo da discricionariedade judicial na solução de casos difíceis pode ser extremamente problemático para a tutela de valores como segurança e justiça, além de poder comprometer a legitimidade democrática da função judicial. Princípios como dignidade da pessoa humana, razoabilidade e solidariedade não são cheques em branco para o exercício de escolhas pessoais e idiossincráticas.

Todavia, defendemos a necessidade da imposição de parâmetros para atividade judicial, que, a nosso ver, deve pautar-se por desenvolver-se dentro do sistema estritamente normativo, bem como deve estar sujeita a um controle intersubjetivo de legalidade e adequação aos valores constitucionais.

\subsection{Dignidade da pessoa humana frente à supremacia do interesse público: a ponderação como critério de satisfação de interesses}

Ante a fática importância que a dignidade da pessoa humana possui na ordem jurídica contemporânea, Sarmento (2007) analisa o conflito entre a satisfação de interesses públicos e privados, afirmando que o princípio da supremacia do interesse público não constitui o critério mais acertado para a resolução do conflito. Por isso, propõe uma solução não por meio da dogmática do direito público, mas pela ponderação equilibrada entre interesses públicos e privados, pautada pelo princípio da proporcionalidade.

Para Sarmento (2003), a ponderação deverá ser efetivada levando-se em consideração: a) cada restrição de interesse em jogo que deverá ser justificada, à medida que se mostra apta a garantir a sobrevivência do interesse contraposto, (b) não houver solução menos gravosa e (c) o benefício logrado com a restrição a um interesse "compensar o grau de sacrifício imposto ao interesse antagônico”, ou seja, a partir da incidência do princípio da proporcionalidade. 
Binenbojm (2007, p. 150) entende que o "raciocínio ponderativo" leva ao melhor interesse público, ou seja, o fim legítimo que orienta a atuação da Administração Pública. Sendo assim, quando a própria Constituição ou a norma infraconstitucional não esgotarem as possibilidades de ponderação de interesses públicos e privados, caberá à Administração Pública efetuar a ponderação dos interesses envolvidos.

Dessa forma, a ponderação de interesses se apresenta como o melhor instrumento de resolução de conflitos de interesses públicos e privados, por levar em consideração os interesses individuais e coletivos, tomando por parâmetro situações concretas, sem que haja a supremacia de interesses a priori de qualquer das partes envolvidas.

\section{Conclusão}

À luz do Estado Democrático de Direito, marcado pela centralidade da Constituição, concluímos que o princípio da supremacia do interesse público não é o fundamento do regime jurídico administrativo. A supremacia decorre da estrutura jurídica hierarquizada, constitucionalmente disposta e vinculante à Administração Pública e não propriamente a um axioma do Direito Administrativo, vetor de interpretação dos institutos jurídicos administrativos.

O Direito Administrativo, enquanto regime jurídico da atividade administrativa, fixa suas estruturas teóricas no respeito aos preceitos constitucionais, sendo que o Estado, enquanto administrador da res publica, deve impor a promoção e efetivação dos direitos humanos, por excelência, do princípio da dignidade da pessoa humana.

Todavia, considerando-se que os recursos públicos são escassos, imprescindível é a otimização dos gastos públicos que devem voltar a sua aplicação às áreas prioritárias, sempre que possível, em prol do atendimento aos direitos fundamentais sociais.

Por isso, o núcleo dos valores constitucionais que sustentam o princípio da dignidade da pessoa humana e da solidariedade exige a necessidade de que juízes e tribunais adotem certo rigor dogmático e considerem os limites financeiros que são sempre obstáculos à realização de qualquer política pública.

Outrossim, cabe ao Poder Judiciário, iniludivelmente, exercer o importante papel concretizador das políticas públicas, devendo apoiar, especialmente, as destinadas à implementação do princípio constitucional da dignidade da pessoa humana, contanto que haja numerário suficiente para o seu atendimento pelo Poder Público. 
Por sua vez, o interesse público não pode estar a inteiro arbítrio do administrador, mas deve ser aferido por meio de um juízo de ponderação a fim de que nenhum dos interesses envolvidos prevaleça sobre o outro.

Por fim, os parâmetros da atuação judicial, mesmo quando colhidos fora do sistema estritamente normativo, também devem corresponder ao sentimento social e estar sujeitos a um controle intersubjetivo de racionalidade, legitimidade e ponderação de valores.

\section{REFERÊNCIAS}

ARAGÃO, A. S. de. A "Supremacia do Interesse Público" no advento do Estado de Direito e na hermenêutica do Direito Público contemporâneo. In: SARMENTO, D. Interesses públicos versus interesses privados: descontruindo o Princípio de Supremacia do Interesse Público. Rio de Janeiro: Lumen Juris Editora, 2007.

ÁVILA, H. B. Repensando o "Princípio da Supremacia do Interesse Público sobre o Particular”. In: SARMENTO, D. Interesses públicos versus interesses privados: descontruindo o Princípio de Supremacia do Interesse Público. Rio de Janeiro: Lumen Juris Editora, 2007.

BARROSO, L. R. A constitucionalização do direito e suas repercussões no âmbito administrativo. In: ARAGÃO, A. S. de; MARQUES NETO, F. de A. Direito Administrativo e seus novos paradigmas. Belo Horizonte: Fórum Editora, 2008.

BINENBOJM, G. Da Supremacia do interesse público ao dever de proporcionalidade: um novo paradigma para o Direito Administrativo. In: SARMENTO, Daniel. Interesses públicos versus interesses privados: descontruindo o Princípio de Supremacia do Interesse Público. Rio de Janeiro: Lumen Juris Editora, 2007.

BOBBIO, N. A era dos direitos. Rio de Janeiro: Campus Editora, 1992.

BORGES, A. G. Supremacia do interesse público: desconstrução ou reconstrução? Revista Interesse Público, Porto Alegre, n. 37, p. 29-48, maio/jun., 2006.

DI PIETRO, M. S. Z. Direito Administrativo. 19. ed. São Paulo: Atlas, 2006.

DI PIETRO, M. S. Z.. Direito Administrativo e dignidade da pessoa humana. Revista Digital de Direito Administrativo, v. 1, n. 2, p. 260-279, 2014. Disponível em: https://www.revistas.usp.br/rdda/article/ view/74853. Acesso em: 25 mai. 2020.

ESCOLA, H. J. El interes público como fundamento del derecho administrativo. Buenos Aires: Depalma, 1989.

FLORES, J. H. Teoria crítica dos direitos humanos: os direitos humanos como produtos culturais. Rio de Janeiro: Lumen Juris 2009. 
· JUCILÉIA DE SOUZA LIMA

GRINOVER, A. P. O controle de políticas públicas pelo Poder Judiciário. In: O Processo: estudos e pareceres. 2. ed. São Paulo: DPJ Editora, 2009.

HERKENHOF, J. B. Filosofia do Direito. Rio de Janeiro: GZ Editora, 2010. JUSTEN FILHO, M. Curso de Direito Administrativo. 4. ed. rev. e atual. São Paulo: Saraiva, 2009.

MELLO. C. A. B. de. Curso de Direito Administrativo. 19. ed. São Paulo: Malheiros, 2005.

MEIRELLES, H. L. Direito Administrativo brasileiro. 25. ed. São Paulo: Malheiros, 2000.

MOREIRA NETO, D. de F. Quatro paradigmas do Direito Administrativo pós-moderno. Belo Horizonte: Fórum, 2008.

OSÓRIO, F. M. Existe uma supremacia do interesse público sobre o privado no Direito Administrativo brasileiro? Revista de Direito Administrativo, Rio de Janeiro, n. 220, p. 69-107, abr./jun. 2000.

PIOVESAN. F. Direitos humanos e o direito constitucional internacional. 8. ed. rev. amp. e atual. São Paulo: Saraiva, 2007.

SARMENTO, D. Interesses públicos versus interesses privados: descontruindo o Princípio de Supremacia do Interesse Público. Rio de Janeiro: Lumen Juris, 2007.

SARMENTO, D. A ponderação de interesses na Constituição Federal. Rio de Janeiro, Lumen Juris: 2003. 